\title{
Design and Application of Silica Micro-Clusters for Microalgae Separation
}

\author{
Tan K.Y. ${ }^{1}$, Chng L.M. ${ }^{1}$, Leong S.S. ${ }^{2}$, Lim J.K. ${ }^{2}$, Chan D.J.C. ${ }^{2}$, Masrul M. ${ }^{3}$ Toh P.Y. ${ }^{1 *}$ \\ ${ }^{1}$ Department of Petrochemical Engineering, Faculty of Engineering and Green Technology, Universiti Tunku \\ Abdul Rahman, Kampar 31900, Perak, Malaysia \\ ${ }^{2}$ School of Chemical Engineering, Universiti Sains Malaysia, Nibong Tebal, 14300 Penang, Pulau Pinang, \\ Malaysia. \\ ${ }^{3}$ School of Biological Sciences, Universiti Sains Malaysia, 11800 Penang, Pulau Pinang, Malaysia.
}

*Corresponding Author: tohpy@utar.edu.my

Article History

Received: October 24, 2018 Received in revised form: November 2, 2018 Accepted: November 17, 2019 Published Online: February 10, 2019

\begin{abstract}
Eutrophication has attracted social's attention as it is a worldwide problem in freshwater aquatic ecosystem. Therefore, cultivation of microalgae in nutrient-rich medium can serve as wastewater treatment as they remove the pollutants from aquatic environment and the microalgal biomass can produce biofuels or other valuable bioproducts. Although microalgae harvesting by gravity sedimentation method is less expensive but it promotes slow sedimentation rate and increases the possibility of biomass deteriorates during harvesting process. In this research, the silica micro-clusters (SMCs) was being synthesized and surface functionalized by positively charged chitosan to improve the attachment with microalgal cells in order to promote rapid microalgae removal through sedimentation. The cell removal efficiency of Chlorella sp. can reach up to $99.41 \pm 0.64 \%$ by using $1 \mathrm{~g} / \mathrm{L}$ of surface functionalized SMCs (SF-Si). Moreover, it also tended to promote high rate of cell sedimentation at $22.71 \pm 3.02 \mathrm{~cm} / \mathrm{h}$ which was about 162 times faster than self-sedimentation. This method of silica-aided-sedimentation (SAS) had proven effective to harvest the multi-species microalgal cells which collected from Tualang lake, Perak, and achieved cell separation efficiency up to $100 \%$ by $80 \mathrm{mg} / \mathrm{L}$ of SF-Si.
\end{abstract}

Keywords: Silica micro-clusters; Surface functionalization; Microalgae; Cell separation efficiency; Sedimentation rate.

\subsection{INTRODUCTION}

Gravity sedimentation is the cheapest and easiest method among the conventional method for microalgae harvesting. However, the biomass harvested from this method is wet and not compact due to slow settling rate [1]. The surface of microalgae carries a net negative charge. The cells with similar surface charge will repel with each other due to the electrostatic repulsion interaction and promote very slow sedimentation. Moreover, the microalgal biomass might loss in quantity due to the continuous respiration of cells and also the possibility of decompose by bacterial after maintained in static condition for a long duration [2].

Recently, the separation of microalgae by using iron oxide nanoparticles through magnetophoretic separation method is being studied actively because of its advantages against the conventional cell separation method [3-5]. However, this method will become unrealistic for large scale environmental application due to the potential nanotoxicity effect from the nanoparticles toward the aquatic lifes [6]. This is due to the difficulty to completely collect the nanoparticles from medium and hence causes the leakage of nanoparticles into the environmental water body. From the study of research team of Toh, a total $20 \mathrm{mg} / \mathrm{L}$ of iron oxide nanoparticles or more were found toxic to Chlorella $\mathrm{sp}$. microalgae. This was due to the suspending iron oxide nanoparticles had blocked the light from reach to cell surface and hence retarded the growth of microalgae [7]. From the review of Demir's research team, the sizes of Nannochloropsis sp. and Isochrysis sp. marine microalgae were found decreasing along the cultivation day when their growing medium was contaminated by iron oxide nanoparticles [8]. The research team 
of Ayatallahzadeh Shirazi found that the morphology of microalgal cells were being changed by the $\mathrm{Al}^{3+}$ ions after the culture medium contaminated by aluminum oxide nanoparticles and finally causes shrinkage of microalgal cells [9]. Besides that, the research team of Karunakaran proved that the nanoparticles was more toxic than the micron sized particles. The nanoparticles promote better adsorption ability compare to micron sized particles due to its high specific surface area. The accumulated nanoparticles on the surface of microalgae had blocked the light from reach to the cell for photosynthesis and thus inhibited the growth of microalgae [10]. Above studies proved that the main factor that promotes the toxicity of nanoparticles is the size of attaching agent. Therefore, the size of attaching agent will be the key factor to confirm the reliability of the separation technology on environmental application.

In this study, particles in micron size are proposed to be used to replace the nanoparticles. The magnetic responsive property on particles is not required because the micron-sized particles tend to settle down easily. The silica is being used as sedimentation-aiding agent (SAA) to shorten the duration of cell sedimentation by increase the total mass of the microalgal cell flocs. Silica is selected as it is abundant [11], non-toxic [12], chemicaly inert, processable, biocompatible and also can be modified easily [13]. Hence, the detachment of silica from microalgal biomass can be avoid when send the biomass waste to land spreading for nutrient recovery purpose. The silica will finally return back to the ground as it is the main component in soil. This new method named silica-aided-sedimentation (SAS). According to the above concern, this study will synthesize silica micro-clusters (SMCs) and then surface functionalize the SMCs so that SMCs able to attach on microalgal cells effectively. Next, the cell separation efficiency and settling rate of cells promoted by SAA using SAS method will be investigated too. Moreover, the feasibility of SAS method to harvest microalgal biomass from environmental freshwater water body will be demonstrated as well. The freshwater Chlorella sp. microalgae was being employed as a model in this study.

\subsection{METHODOLOGY}

\subsection{Materials}

The chitosan (Average molecular weight of 190,000-310,000 g/mol) was supplied by Sigma-Aldrich, Inc. Acetic acid (99.8 $\%)$ and aqueous ammonia (30 \%) were obtained from R\&M Chemicals. Isopropanol (99.8 \%) and ethanol (30\%) were obtained from SIME Scientific, while the tetraethyl orthosilicate (TEOS) (98\%) was obtained from ACROS Organics.

\subsection{Cultivation of Chlorella sp. Microalgae}

The Chlorella sp. microalgae was cultivated in $250 \mathrm{~mL}$ of Bold's Basal Medium (BBM) in $500 \mathrm{~mL}$ conical flask. The flask and culture medium were autoclaved at temperature of $121^{\circ} \mathrm{C}$ for 15 minutes. The initial cell density of Chlorella sp. cells was at $1.936 \times 10^{5}$ cells $/ \mathrm{mL}$. The hemocytometer was employed for cell counting purpose. The microalgae were cultivated under continuos lighting and air bubbling 14 days. The surface charge of Chlorella sp. microalgae was measured by using Malvern Zetasizer Nano.

\subsection{Preparation of Chitosan Solution}

The chitosan solution at concentration of $25 \mathrm{~g} / \mathrm{L}$ was prepared. The $1 \%$ acetic acid solution was used to dissolve the chitosan powder. The solution was stirred overnight in order to achieve complete dissolution. The surface charge of chitosan was measured by using Malvern Zetasizer Nano.

\subsection{Synthesis of SMCs}

The SMCs was prepared by Stober process. Firstly, the isopropanol was mixed with aqueous ammonia and deionized water for 5 minutes. The TEOS was then mix with the solution and stirred for 8 hours at $120 \mathrm{rpm}$. The solution was incubated for 24 hours in order to ensure complete reaction happened. The synthesized SMCs were collected by centrifugation at $2500 \mathrm{rpm}$ for 5 minutes. The collected SMCs was washed three times with deionized water in order to remove the unreacted chemical and then dried through freeze drying process for 24 hours.

\subsection{Surface Functionalization of SMCs}

The SMCs was surface functionalized by low molecular weight chitosan solution. A total $16 \mathrm{~mL}$ of SMCs in deionized water, at concentration of $10 \mathrm{~g} / \mathrm{L}$, was added into $64 \mathrm{~mL}$ of chitosan solution, at concentration of $25 \mathrm{~g} / \mathrm{L}$, for surface functionalization. After stirring for 24 hours, the surface functionalized SMCs were collected by centrifugation at $2500 \mathrm{rpm}$ for $5 \mathrm{minutes}$. The 
collected surface functionalized SMCs were then washed with deionized water for three times in order to remove excessive chitosan. Then, the surface functionalized SMCs was dispersed into deionized water at respective concentration in order to achieve desired concentration, at 10,50,100,150,200,300,500,1000 mg/L, in cell medium after $1 \mathrm{~mL}$ of surface functionalized SMCs (SF-Si) was added into $15 \mathrm{~mL}$ of cell medium. The average sizes of bare SMCs (Ba-Si) and SF-Si were measured by using Particle Size Analyzer (Malvern Mastersizer 2000). The surface charge of Ba-Si and SF-Si were measured by using Malvern Zetasizer Nano.

\subsection{Separation of Microalgae through SAS Method}

The cell sample at cell density of $3 \times 10^{-7}$ cell $/ \mathrm{mL}$ was used for each test. The desired cell density of the cell medium was achieved by appropriate dilution using the supernatant of centrifuged medium. A total of $1 \mathrm{~mL}$ SMCs was added into $15 \mathrm{~mL}$ of the cell medium and the mixture was stirred at $120 \mathrm{rpm}$ for 20 minutes under room temperature. Then, the flocs in samples were left to settle down for 60 minutes. After that, a total $4 \mathrm{~mL}$ of sample was collected at about $1 \mathrm{~mm}$ distance below the liquid surface and then was measured by UV-Vis spectrophotometer at wavelength of $660 \mu \mathrm{m}$. The cell separation efficiency was calculated by using the formula below:

$$
\text { cell separation efficiency }(\%)=\frac{\mathrm{ABS}_{\mathrm{o}}-\mathrm{ABS}}{\mathrm{ABS}_{\mathrm{o}}-\mathrm{ABS}_{\text {centrifuged }}}
$$

Where $\mathrm{ABS}_{\mathrm{o}}$ is absorbance intensity of microalgal cell medium, $\mathrm{ABS}$ is absorbance intensity of sample and $\mathrm{ABS}$ centrifuged is absorbance intensity of centrifuged clear medium. The cell sedimentation rate was determined by measuring the sedimentation distance of the cells over time.

\subsection{RESULTS AND DISCUSSION}

\subsection{Characteristics of Surface Functionalization of SMCs}

In this study, SMCs was used as attaching agent in order to promote effective attachment with microalgal cells to enhance the cell separation efficiency and sedimentation rate. Results in Table 1 showed that the Ba-Si and Chlorella sp. cells were in negative charge, which were at $-2.9860 \pm 0.2956 \mu \mathrm{mcm} / \mathrm{Vs}$ and $-2.4851 \pm 0.0742 \mu \mathrm{mcm} / \mathrm{Vs}$ respectively. The Ba-Si and Chlorella sp. microalgae tend to repel each other by electrostatic repulsion force.

Table 1. Electrophoretic mobility of different surfaces

\begin{tabular}{cc}
\hline Surface & Electrophoretic Mobility $(\mu \mathrm{mcm} / \mathrm{Vs})$ \\
\hline Chitosan & $2.1190 \pm 0.8783$ \\
Chlorella sp. & $-2.4851 \pm 0.0742$ \\
Multi-species microalgae & $-1.6250 \pm 0.1333$ \\
Ba-Si & $-2.9860 \pm 0.2956$ \\
SF-Si & $2.3707 \pm 0.1543$ \\
\hline
\end{tabular}

The research team of Kim shown that the molecules with chelating amine sites can attach to the surface of silica and then form agglomerations or gel-like networks between silica particles after stirring. They concluded that the molecules that contain positively charged amine groups can use to modify the surface of silica as shown in Figure 1 [14]. Therefore, the positively charged chitosan, at $2.1190 \pm 0.8783 \mu \mathrm{mcm} / \mathrm{Vs}$ (Table 1), which consists of amine groups was being used to modify the surface of SMCs. A layer of chitosan was being coated onto the surface of Ba-Si. After surface modification or functionalization, the surface charge of SF-Si has become positive charge that was at $2.3707 \pm 0.1543 \mu \mathrm{mcm} / \mathrm{Vs}$ (Table 1). The SF-Si had flocculated to form micro-cluster structure as shown in Figure 2 after stirring process. 


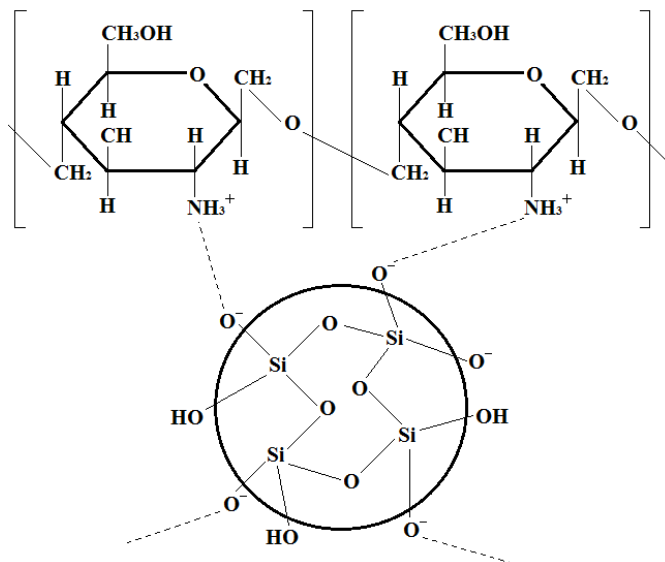

Figure 1. Schematic diagram of interaction between silica and chitosan [15]

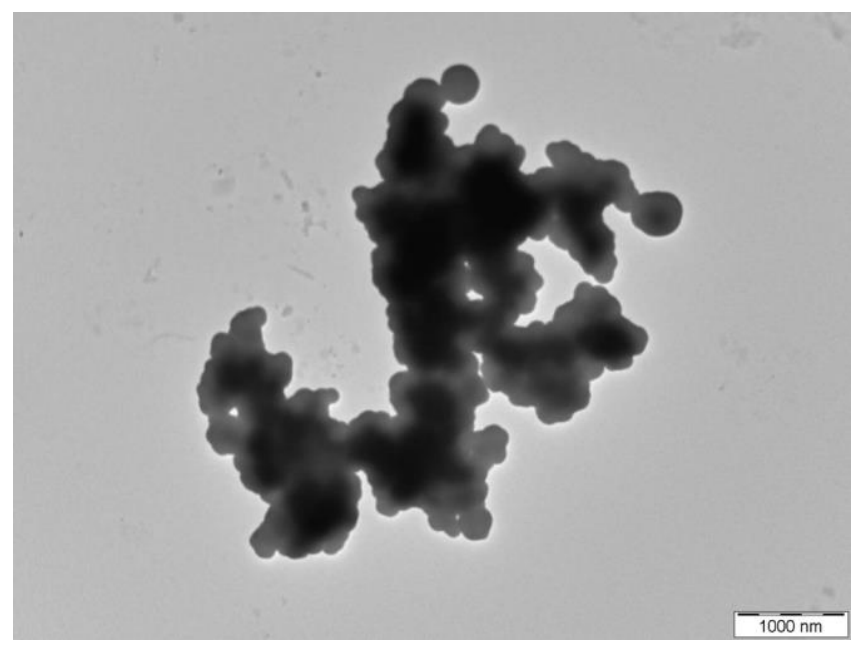

Figure 2. TEM Image of SMCs

The particle size analyser was being employed to measure the size distribution of Ba-Si and SF-Si. Result in Figure $3 b$ showed that the average size of SF-Si was at $8.20 \mu \mathrm{m}$ which was larger than Ba-Si at $7.49 \mu \mathrm{m}$. The effective attachment of SMCs with each other was promoted by stirring process when the SMCs were being surface functionalized by chitosan. The collision frequency between SMCs and chitosan was being increased by stirring process and hence promote attachment with each other [16]. From literature review, chitosan is a well known flocculant that was largely used in wastewater treatment by the flocculation method [17]. The suspended solid in wastewater will flocculate to become large flocs or clusters after stirring process [18]. The sizes of the two types of SMCs were in range of about $2.5 \mu \mathrm{m}$ to $40 \mu \mathrm{m}$ as shown in Figure 3 . The peak in Figure 3 that had shifted to right proved that of the formation of micro-cluster SF-Si is sucessful. 

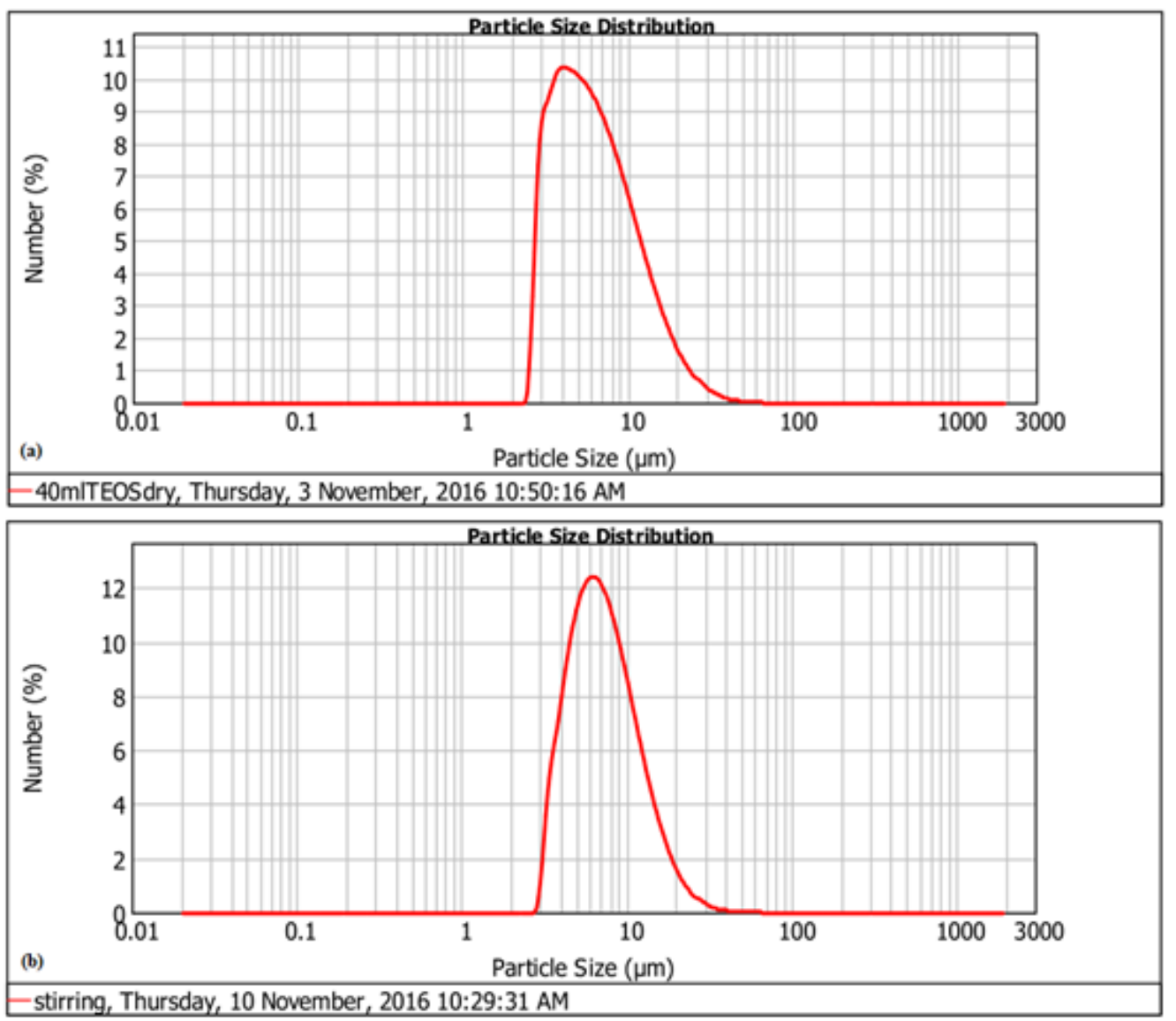

Figure 3. Particle size distributions of (a) Ba-Si and (b) SF-Si

\subsection{Microalgae Separation by SAS Method}

The cell separation efficiency promoted by SAS method was studied. Ba-Si failed to promote cell separation as shown in Figure 4. The cell separation was maintained in range of $40 \%$ to $50 \%$ indicated that the cells were settle down through gravitational force without aided by SMCs. This is due to the Ba-Si and cells were in negative charge as shown in Table 1. Hence, Ba-Si and cells will repel with each other. So, the Ba-Si failed to attach on cell surface.

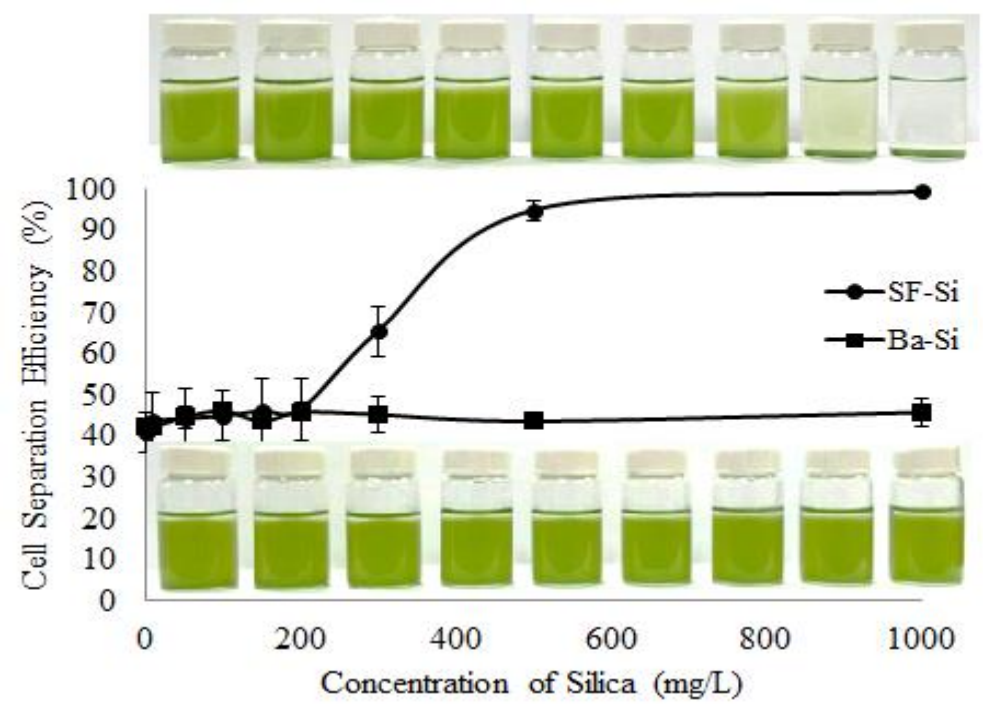

Figure 4. The cell separation efficiency of Chlorella sp. microalgae at different dosage of SMCs 
After the Ba-Si being surface functionalized with chitosan, the formed SF-Si had become positive charge, at $2.3707 \pm 0.1543$ $\mu \mathrm{mcm} / \mathrm{Vs}$ (Table 1), which was in opposite charge with microalgal cells $(-2.4851 \pm 0.0742 \mu \mathrm{mcm} / \mathrm{Vs})($ Table 1$)$. Hence, the SF-Si can attached onto the surface of microalgal cells effectively through electrostatic attraction. Furthermore, the collision frequency between two interacting surfaces, SF-Si and cells, were increased by stirring process and hence they can come into contact with each other to achieve effective attachment, promote agglomeration and rapid sedimentation of cell suspension $[16,19]$. The aggregation of SF-Si-attached-cells flocs was promoted by the bridging mechanism of chitosan chains that extended out from the surface of SF-Si during stirring process [20]. Therefore, the silica can attach onto cell surface effectively after stirring.

The sedimentation rate of Chlorella sp. cells when without (control sample) and with SF-Si were investigated. Result in Figure 5 showed that the control cell sample performed slow self-sedimentation at rate of $0.14 \pm 0.01 \mathrm{~cm} / \mathrm{h}$. The negatively charged microalgal cells tend to repel with each other and form a stable suspension with slow sedimentation rate.

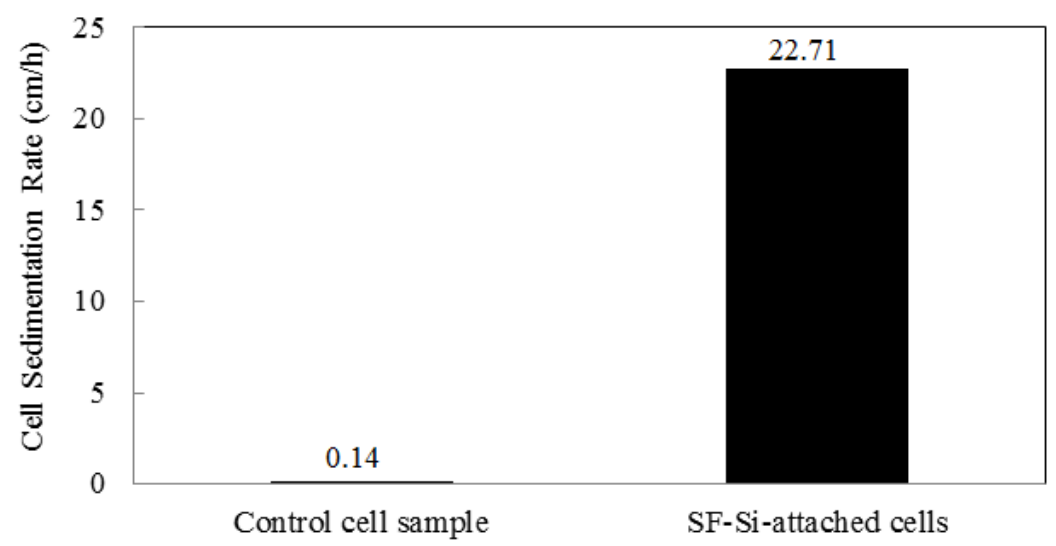

Figure 5. Sedimentation rate of Chlorella sp. microalgae before and after the addition of SF-Si

When the SF-Si was being attached onto cells effectively, the sedimentation rate of cells was being improved significantly. The sedimentation rate of SF-Si-attached-cell was about 162 times faster than the self-sedimentation rate of cells. Therefore, the SAS method by using SF-Si followed by stirring attachment method has been proven can enhance the sedimentation rate of microalgal cells effectively to meet time effectiveness.

\subsection{Feasibility of SAS Method to Harvest Microalgae from Environmental Freshwater System}

The feasibility of the proposed SAS method onto the environmental freshwater system was being studied. The water sample (Figure 6) that was crowded with multi-species microalgae was being collected from the Tualang Lake located in Perak.

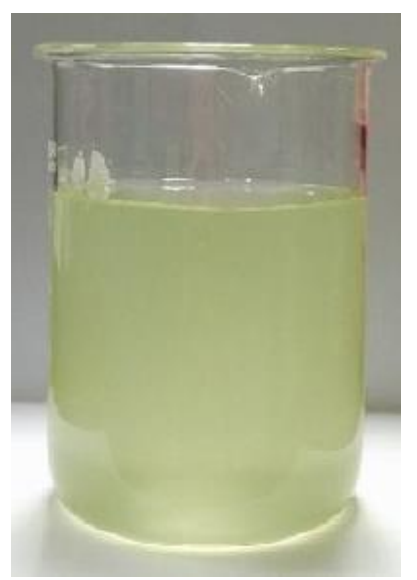

Figure 6. Water sample crowded with microalgae that collected from Tualang Lake, Perak 
After the addition of $80 \mathrm{mg} / \mathrm{L} \mathrm{SF-Si}$ into the sample, the microalgal cells were being removed successfully and achieved up to $100 \%$ of cell separation efficiency (Figure 7). The SF-Si that carried positive charge at $2.3707 \pm 0.1543 \mu \mathrm{mcm} / \mathrm{Vs}$ (Table 1) was attached onto the multi-species microalgae that carried a net negative charge at $-1.6250 \pm 0.1333 \mu \mathrm{mcm} / \mathrm{Vs}(\mathrm{Table} 1)$ effectively. The effective attachment between both surfaces through electrostatic attraction led to charge neutralization, agglomeration and sedimentation [3,21]. This study has proven that the SAS method by using SF-Si was effective to harvest multi-species of microalgae from surrounding freshwater system. The species of freshwater microalgae will not restrict the performance of SAS method [22].

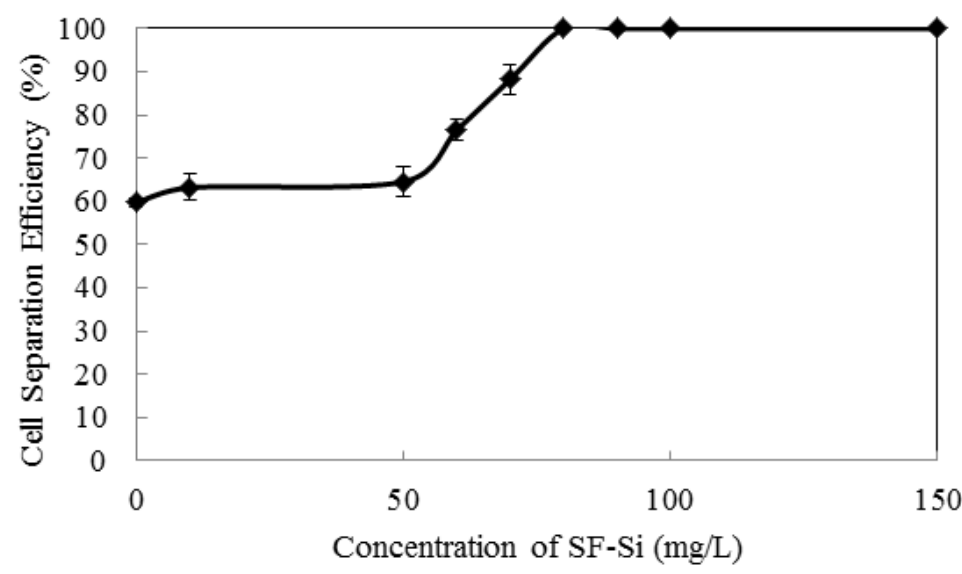

Figure 7. Cell separation efficiency of multi-species microalgae in a function of concentration of SF-Si

\subsection{CONCLUSION}

In this study, the SAS method was being proven can improve the cell separation efficiency of microalgae and sedimentation rate effectively. The SMCs with an average size of $7.49 \mu \mathrm{m}$ and at negative charge at $-2.9860 \pm 0.2956 \mu \mathrm{mcm} / \mathrm{Vs}$ was being synthesized successfully. After surface functionalization, positively charged SF-Si at $2.3707 \pm 0.1543 \mu \mathrm{mcm} / \mathrm{Vs}$ was formed. The positively charged SF-Si tends to attach onto cell surface effectively and achieved cell separation efficiency up to 99.41 $\pm 0.64 \%$ and sedimentation rate at $22.71 \pm 3.02 \mathrm{~cm} / \mathrm{h}$ by adding $1 \mathrm{~g} / \mathrm{L}$ of SF-Si. Furthermore, the SAS method was feasible to harvest the multi-species microalgal cells which collected from Tualang lake, Perak and achieved cell separation efficiency up to $100 \%$ by $80 \mathrm{mg} / \mathrm{L}$ of SF-Si. The stirring process promotes collision between SF-Si and cells. Also, stirring permits adsorption, bridging, charge neutralization, aggregation and destabilization to occur, and followed by gravimetric sedimentation. This study showed that the SAS method can be used to harvest microalgal biomass effectively without restricted by the species of microalgae. The lipids contents of the microalgal biomass harvested by SAS method should be further studied in order to confirm its suitability for large scale biofuel production purpose.

\section{Acknowledgements}

This work is supported by UTAR Research Fund (UTARRF) from UTAR (Grant No. 6200/TC6), Research University Grant for Individual (GUI) (Grant No. 814209), Fundamental Research Grant Scheme (FRGS) (Grant No. 6071207), and eScience Fund from MOSTI (Grant No. 6013412).

\section{References}

[1] Jihar, H. S., D. Abhijeet, P. Kushal, P. Keyur, and V. M. Alpesh. 2014. A comprehensive overview on various method of harvesting microalgae according to Indian perspective. International Conference on Multidisciplinary Research and Practice: 1: 313-317.

[2] Singh, M., R. Shukla, and K. Das. 2013. Harvesting of microalgal biomass. Biotechnological Applications of Microalgae: 77-88.

[3] Xu, L., C. Guo, F. Wang, S. Zheng, and C. Z. Liu. 2011. A simple and rapid harvesting method for microalgae by in situ magnetic separation. Bioresource Technology: 102: 10047-10051.

[4] Lim J. K., D. J. C. Chan, S. A. Jalak, P. Y. Toh, N. H. Yasin, B. W. Ng, and A. L. Ahmad. 2012. Rapid Magnetophoretic Separation Of Microalgae. Small: 8: 1689-1692. 
[5] Toh P. Y., B. W. Ng, A. L. Ahmad, D. J. C. Chan, and J. K. Lim. 2014. Magnetophoretic separation of Chlorella sp.: Role of Cationic Polymer Binder. Process Safety and Environmental Protection: 92: 515-521.

[6] Jiang G. X., Z. Y. Shen, J. F. Niu, L. P. Zhuang, and T. D. He. 2011. Nanotoxicity of Engineered Nanomaterials In The Environment. Progress in Chemistry: 23: 1769-1781.

[7] Toh P. Y., W. Y. Tai, A. L. Ahmad, J. K. Lim, and D. J. C. Chan. 2015. Toxicity of Bare And Surfaced Functionalized Iron Oxide Nanoparticles Towards microalgae. International Journal of Phytoremediation: 18: 643-650.

[8] Demir V., M. Ates, Z. Arslan, M. Camas, F. Celik, C. Bogatu, and S. S. Can. 2015. Influence of Alpha And Gamma-Iron Oxide Nanoparticles On Marine Microalgae Species. Bulletin of Environmental Contamination and Toxicology: 95: 752-757.

[9] Ayatallahzadeh Shirazi, M., F. Shariati, A. K. Keshavarz, and Z. Ramezanpour. 2015. Toxic Effect Of Aluminum Oxide Nanoparticles On Green Micro-Algae Dunaliella Salina. International Journal of Environmental Research: 9: 585-594.

[10] Karunakaran, G., R. Suriyaprabha, V. Rajendran, and N. Kannan. 2015. Toxicity Evaluation Based On Particle Size, Contact Angle And Zeta Potential of $\mathrm{SiO}_{2}$ and $\mathrm{Al}_{2} \mathrm{O}_{3}$ on the Growth Of Green Algae. Advances in Nano Research: 3: 243-255.

[11] Live Strong. 2011. What is Silicon Dioxide In Supplements? http://www.livestrong.com/article/520897-what-is-silicon-dioxide-in-supplements/. Accessed 11 July 2016.

[12] MemPro Material. 2016. Silica Dioxide Nanofibre Mateial. http://mempro.com/products/ceramic-nanofiber-materials/silicon-dioxide-nanofibermaterial/. Accessed 11 July 2016.

[13] Li, B. J., X. Y. Zou, Y. B. Zhao, L. Sun, and S. L. Li. 2013. Biofunctionalization of Silica Microspheres For Protein Separation. Materials Science and Engineering $C: 33: 2595-2600$.

[14] Kim, K. M., H. M. Kim, W. J. Lee, C. W. Lee, T. I. Kim, L. K. Lee, J. Y. Jeong, S. M. Paek, and J. M. Oh. 2014. Surface Treatment Of Silica Nanoparticles For Stable And Charge-Controlled Colloidal Silica. Journal of International Journal of Nanomedicine: 9: 29-40.

[15] Budnyak, T. M., I. V. Pylypchuk, V. A. Tertykh, E. S. Yanovska, and D. Kolodynska. 2015. Synthesis and Adsorption Properties Of Chitosan-Silica Nanocomposite Prepared By Sol-Gel Method. Nanoscale Research Letters: 10: 87.

[16] Ahmad, A. L., N. H. M. Yasin, D. J. C. Chan, and J. K. Lim. 2011. Optimization of Microalgae Coagulation Process Using Chitosan. Chemical Engineering Journal: 173: 879-882.

[17] No, H. K., and S. P. Meyers. 2000. Application of Chitosan For Treatment Of Wastewaters. Review of Environmental Contamination and Toxicology: 163: 1-27.

[18] Koohestanian, A., M. Hosseini, and Z. Abbasian. 2008. The Separation Method For Removing Of Colloidal Particles From Raw Water. Journal of Agricultural and Environmental Science: 4: 266-273.

[19] Wu, X., X. Ge, D. Wang, and H. Tang. 2007. Distinct Coagulation Mechanism And Model Between Alum And High $\mathrm{Al}_{13}-\mathrm{PACl}$. Colloids and Surfaces A: Physicochemical and Engineering Aspects: 305: 89-96.

[20] Zhou, Y., and G. V. Franks. 2006. Flocculation Mechanism Induced By Cationic Polymers Investigated By Light Scattering. Langmuir: 22: 67756786.

[21] Roussy, J., M. Van Vooren, B. A. Dempsey, and E. Guibal. 2005. Influence of Chitosan Characteristics On The Coagulation And The Flocculation Of Bentonite Suspensions. Water Research: 39: 3247-3258.

[22] Hadjoudja, S., V. Deluchat, and M. Baudu. 2010. Cell Surface Characterisation of Microcystis aeruginosa and Chlorella vulgaris. Journal of Colloid and Interface Science: $342:$ 293-299. 